\title{
The Effectiveness of Extended Schedules of Heating Regulation at CHP Plants with Decreasing Normative Design Temperature of the Supply Water
}

\author{
Suvorov D.M., Tatarinova N.V., Lyskova E.A. \\ Vyatka State University \\ Kirov, Russian Federation
}

\begin{abstract}
The aim of the work is a computational study of the effectiveness of the extended schedules of heating regulation at steam turbine CHPPs with a decrease in the normative design temperature of the supply water. The study was carried out on adequate mathematical models of CHP turbines and heat supply systems, considering heat pipelines' actual diameters and lengths. The main energy efficiency indicator is the specific reference fuel consumption for electricity supply, calculated under comparable conditions for the operating modes of turbine plants and the load of the heat supply system. The study took into account the electricity consumption for the drive of network pumps, standard heat losses in heating networks and the electricity generation for the heat consumption of CHPPs. The study results allowed for the first time to determine the integral indicators of the energy efficiency of work during the transition of CHPPs from the normative design ones to the temperature schedules reduced by the temperature of the supply water. At the same time, the calculations revealed the limitations on the parameters of the extended schedules of regulation when transitioning to reduced temperature schedules. The most important results of the work should also be attributed to the determination of the optimal schedules of the temperature of the supply water for different values of the district heating coefficient of the CHPP. The results obtained are essential for assessing the efficiency of the transition of heat supply systems to reduced supply water's design temperatures when using modern heating regulation schedules.
\end{abstract}

Keywords: heat supply system, heating load, heating regulation, temperature schedule, CHPP, specific reference fuel consumption, delivery water.

DOI: https://doi.org/10.52254/1857-0070.2021.4-52.10

UDC: 697.34

Eficiența graficelor extinse de reglare a termoficării șa CET la scăderea temperaturii calculate a apei din conducta tur

Suvorov D.M., Tatarinova N.V., Lyskova E.A.

Universitatea de Stat din Veatka

Kirov, Federaţia Rusă

Rezumat. Scopul lucrării este cercetarea prin calculare a eficienței graficelor de reglare a termoficării la CET cu turbine cu abur la o scădere a temperaturii de proiectare a apei din conducta tur. Studiul a fost realizat pe modele matematice adecvate ale instalațiilor cu turbine pentru centrale termice și sisteme de alimentare cu căldură, ținând cont de diametrele și lungimile reale ale rețelei de încălzire. Principalul indicator al eficienței energetice este determinat consumul specific de combustibil echivalent pentru generarea energiei electrice, calculat în condiții comparabile pentru regimurile de funcționare ale instalațiilor cu turbine și pentru sarcina sistemului de alimentare cu căldură. Totodată, au fost luate în considerare consumul de energie electrică pentru antrenarea pompelor de rețea, pierderile normate de căldură în rețelele de termoficare și generarea de energie electrică din consumul de căldură al CET. Parametrii integrali de eficiență pentru perioada de încălzire au fost determinați ținând cont de durata menținerii temperaturii în fiecare interval de un grad, iar calculele au fost efectuate pentru fiecare temperatură reprezentată de un număr întreg a aerului din exterior. În rezultatul cercetărilor au fost determinați indicatorii eficienței energetice la trecerea CET de la graficele proiectate de temperatură la cele de temperatură redusă a apei din conducta tur, cât păstrând reglarea inițială a termoficării, atât și la trecerea graficelor extinse de reglare a termoficării. Cele mai importante rezultate ar trebui să includă și determinarea graficelor optime de temperatură pentru alimentarea cu apă din linia de alimentare a rețelei de încălzire la diferite valori ale coeficientului de termoficare al CET. Rezultatele obținute sunt de mare importanță pentru aprecierea eficienței tranziției sistemelor de alimentare cu căldură la temperaturi de proiectare calculate scăzute ale apei din conducta tur utilizând grafice actuale de reglare cantitativă și calitativă a termoficării.

Cuvinte-cheie: sistem de aprovizionare cu energie termică, sarcină termică, reglarea termoficării, grafic de temperatură, CET, consum specific de combustibil echivalent, apă de rețea.

(C) Суворов Д.М., Татаринова Н.В.,

Лыскова Е.А., 2021 


\section{Эффективность расширенных графиков регулирования отопления на ТЭЦ при понижении расчетной температуры прямой сетевой воды Суворов Д.М., Татаринова Н.В., Лыскова Е.А. Вятский государственный университет Киров, Российская Федерация}

Аннотация. Целью данной работы является расчетное исследование эффективности расширенных графиков регулирования отопления на паротурбинных ТЭЦ при понижении расчетной температуры прямой сетевой воды. Исследование выполнено на адекватных математических моделях турбоустановок ТЭЦ и систем теплоснабжения с учетом реальных диаметров и длин тепловых магистралей. Основным показателем энергетической эффективности определен удельный расход условного топлива на отпуск электроэнергии, рассчитанный в сопоставимых условиях по режимам работы турбоустановок и по нагрузке системы теплоснабжения. При этом учитывались затраты электроэнергии на привод сетевых насосов, нормативные тепловые потери в теплосетях и выработка электроэнергии на тепловом потреблении ТЭЦ. Интегральные за отопительный период параметры эффективности определены с учетом длительности стояния температур в каждом одноградусном интервале, причем расчеты проводились по каждой целочисленной температуре наружного воздуха. В результате исследования впервые определены показатели энергетической эффективности при переходе ТЭЦ с проектных на пониженные по температуре прямой сетевой воды температурные графики, как при сохранении исходного регулирования отопления, так и при переходе на расширенные графики регулирования отопления. Выявлены ограничения по параметрам расширенных графиков регулирования при переходе на пониженные температурные графики. К наиболее важным результатам следует также отнести определение оптимальных по температуре сетевой воды в подающей линии теплосети температурных графиков при различных значениях коэффициента теплофикации ТЭЦ. При этом установлено, что снижение максимальной расчетной температуры сетевой воды со 150 до $130^{\circ} \mathrm{C}$ всегда энергетически целесообразно, а ее снижение до $110^{\circ} \mathrm{C}$ целесообразно только при расширенном графике регулирования отопления и при коэффициенте теплофикации, равном единице. Полученные результаты имеют большое значение для оценки эффективности перехода систем теплоснабжения на пониженные расчетные проектные температуры прямой сетевой воды при использовании современных графиков количественнокачественного регулирования отопления.

Ключевые слова: система теплоснабжения, отопительная нагрузка, регулирование отопления, температурный график, ТЭЦ, удельный расход условного топлива, сетевая вода.

\section{ВВЕДЕНИЕ}

В последние годы большинство ТЭЦ в России, а также странах Восточной Европы и Центральной Азии по факту своей работы перешли с проектных (исходных) температурных графиков качественного регулирования тепловой нагрузки в отопительный период на пониженные графики. При этом расчетная температура прямой сетевой воды для этих графиков снижается со $150^{\circ} \mathrm{C}$ или $140^{\circ} \mathrm{C}$ до $130^{\circ} \mathrm{C}$ и даже до $110^{\circ} \mathrm{C}[1]$.

Кроме этого, фактически максимальная температура прямой сетевой воды оказывается еще ниже, чем расчетная для пониженных графиков, из-за наличия срезки графика по достижении определенной температуры, которая может быть на 10-20 градусов ниже расчетной [2].

Помимо этого, наличие нагрузки горячего водоснабжения (ГВС) приводит к наличию спрямления по температуре прямой сетевой воды, которая при наличии закрытых систем водоснабжения не может быть ниже $73-77^{\circ} \mathrm{C}$; поэтому при положительных температурах наружного воздуха при исходном температурном графике $150 / 70^{\circ} \mathrm{C}$ фактически в системах теплоснабжения имеет место не качественное, а количественное регулирование тепловой нагрузки. При переходе на пониженные температурные графики зона срезки распространяется в сторону более низких температур воздуха и может охватывать зону до минус $10-15^{\circ} \mathrm{C}$ (в зависимости от климатических и иных условий). В такой ситуации обычные элеваторные системы регулирования тепловой нагрузки отопления абонентов становятся неэффективными и уступают место насосным системам регулирования, для которых возможно применение алгоритмов количественно-качественного регулирования.

Авторы из Великобритании [1] аргументом в пользу понижения расчетной температуры прямой сетевой воды существующих сетей (в том числе малых) называют снижение потерь при распределении тепла на 9-10\%. [1,3]. Улучшение показателей системы централизованного теплоснабжения за счет точечной настройки температуры подачи и возврата воды отмечают и авторы из Казахстана [3]. 
Некоторые европейские исследователи (на примерах систем теплоснабжения городов Турина и Гетеборга) на основе большой базы исходных эксплуатационных данных приходят к необходимости реализации более сложной операционной стратегии управления системой теплоснабжения, которая, с одной стороны, обеспечивала бы гарантированные условия комфорта в помещениях, а с другой стороны - снижение годового потребления топлива [4-7].Для достижения этой цели выделяются гранты и создаются математические модели и целые программные комплексы, которые позволяют провести детальные расчеты последствий снижения температурного уровня в тепловых сетях [8-11].

Эти обстоятельства предопределяют целесообразность постепенного перехода систем теплоснабжения на пониженные против исходных или расчетных температурные графики с использованием количественнокачественного регулирования тепловой нагрузки, и в первую очередь - на наиболее термодинамически эффективные расширенные графики регулирования (РГР) по нагрузке отопления, которые становятся возможными при автоматизации тепловых пунктов у абонентов как с точки зрения тепловых режимов работы, так и гидравлических [12-23]. Однако реальных расчетов интегральной (за год или отопительный период) эффективности работы систем теплоснабжения в условиях пониженных температурных графиков в условиях ТЭЦ в отмеченных выше работах зарубежных и отечественных авторов не содержится.

В опубликованных работах по исследованию эффективности перехода на пониженные температурные графики [1-3, 14] не учитывались в полной мере такие факторы, как изменение гидравлических потерь в тепловых сетях и связанные с этим затраты электроэнергии на привод сетевых насосов, изменение стоимости строительства тепловых сетей при необходимости перехода на увеличенные диаметры тепловых магистралей, изменение нормативных тепловых потерь в сетях, а также изменение выработки электроэнергии на тепловом потреблении ТЭЦ при различных граничных условиях их загрузки.

В работах [14, «Расширенный график регулирования отопления: оценка влияния на эффективность паротурбинных ТЭЦ», Пятин А.А., Суворов Д.М. «Проблемы региональной энергетики», №3 (47), 2020, с. 40-55] подроб- но исследована эффективность РГР при переходе на него паротурбинной ТЭЦ со стандартного температурного графика $150 / 70^{\circ} \mathrm{C}$ при срезке $140^{\circ} \mathrm{C}$ и спрямлении при $77^{\circ} \mathrm{C}$ для условий г. Кирова при учете нагрузки отопления. Однако граничные условия исходного температурного графика (ИТГ) и РГР в этих работах не вполне сопоставимы; в частности, различаются расчетные температуры воздуха в отапливаемых помещениях и характер учета внутренних тепловыделений (эти различия, конечно, вытекали из цели и задач исследования и были поэтому абсолютно адекватны). Кроме того, в этих работах исследован только один вариант ИТГ, без перехода на пониженные графики. В данной работе использованы те же математические модели ТЭЦ и методика поградусных расчетов по температурам наружного воздуха для г. Кирова, что и в упомянутых выше работах, но для целей настоящего исследования граничные условия для ИТГ и для РГР выбраны полностью сопоставимыми, в том числе и по отмеченным выше факторам.

Целью данной работы является исследование на адекватных математических моделях в условиях, максимально приближенных к реальным, эффективности расширенных графиков регулирования отопления на паротурбинных ТЭЦ при понижении расчетной температуры прямой сетевой воды с учетом как затрат энергии на привод сетевых насосов, так и нормативных тепловых потерь в сетях, при учете только нагрузки отопления.

Поставленная цель достигается тем, что для моделируемой ТЭЦ учитывается реально возможная дискретность оборудования и реально возможная конфигурация тепловых сетей, которые соответствуют их среднестатистическим характеристикам. В ходе достижения поставленной цели решаются следующие основные задачи. Во-первых, это определение или уточнение показателей, которые характеризуют эффективность работы ТЭЦ в рассматриваемых условиях как применительно к режиму работы при определенной температуре наружного воздуха, так и интегрально за год или за отопительный период. Во-вторых, это определение целесообразности перехода ТЭЦ с проектного на пониженные температурные графики по температуре прямой сетевой воды, как при сохранении исходного регулирования отопления, так и при переходе на расширенные графики регулирования отопления. В-третьих, это опреде- 
ление ограничений по параметрам РГР при переходе на пониженные температурные графики. В-четвертых, это определение оптимальных температурных графиков (как при ИТГ, так и при РГР) по температуре сетевой воды в подающей линии при различных значениях коэффициента теплофикации ТЭЦ. Впятых, наконец, это определение соотношения выработки электроэнергии на тепловом потреблении ТЭЦ при работе на исходном и пониженных температурных графиках, с одной стороны, и при переходе на РГР, с другой стороны, как интегрально за отопительный период, так и при режимах работы ТЭЦ, соответствующих разным температурам наружного воздуха.

\section{МОДЕЛЬНАЯ ТЭЦ, ГРАНИЧНЫЕ УСЛОВИЯ РАСЧЕТОВ И КРИТЕРИИ ЭФФЕКТИВНОСТИ РАБОТЫ СИСТЕМЫ ТЕПЛОСНАБЖЕНИЯ}

Для расчета режимов работы агрегатов модельной ТЭЦ для климатических условий г. Кирова применяется многократно верифицированная программа расчета турбоустановки Т-50-12.8, дающая адекватные результаты расчета эффективности работы для любых паротурбинных ТЭЦ, причем количественно эти результаты практически идентичны для отопительных ТЭЦ с любыми турбоустановками, работающими при начальном давлении пара 12,7 МПа и не имеющих промежуточного перегрева [24]. Для возможности использовать в расчетах конкретные значения диаметров трубопроводов тепловых сетей величина расчетной тепловой нагрузки ТЭЦ была принята конкретной и равной $220 \mathrm{MBT}$, чему соответствует два возможных варианта состава основного оборудования ТЭЦ с турбинами типа T-50-12.8: с одной и с двумя такими турбинами, чему соответствуют достаточно характерные значения коэффициента теплофикации $\alpha$ : 0.5 и 1.0 соответственно (эти значения ограничивают сверху и снизу реально возможные значения данного коэффициента в области эффективной работы таких ТЭЦ).

При $\alpha=0.5$ единственный турбоагрегат при тепловых нагрузках, не превышающих номинальную (110 МВт), работает по электрическому графику с номинальным расходом пара на турбину (72 кг/c), а при более высоких тепловых нагрузках - по тепловому графику с закрытой регулирующей диафрагмой части низкого давления (РД ЧНД). При $\alpha=1.0$ рабо- тают параллельно два агрегата ТЭЦ практически весь отопительный период по электрическому графику также с номинальным расходом пара на турбину (за исключением нескольких десятков часов в год, когда наружная температура воздуха ниже расчетной для проектирования систем отопления).

За исходный температурный график сетевой воды модельной ТЭЦ принят $150 / 70^{\circ} \mathrm{C}$; срезка осуществляется при температуре прямой сетевой воды $\tau_{10}=150^{\circ} \mathrm{C}$, соответствующей расчетной для проектирования систем отопления для г. Кирова температуре воздуха -33 C. Параметры пониженных температурных графиков по сетевой воде без применения РГР приняты равными $130 / 70^{\circ} \mathrm{C}$ и $110 / 70^{\circ} \mathrm{C}$; эти графики рассчитаны без срезки. Поскольку тепловая нагрузка ГВС отсутствует, все графики рассчитаны без спрямления вплоть до температуры включения отопления $+8^{\circ} \mathrm{C}$.

Для исследуемой модельной системы теплоснабжения выбраны две основные тепловые магистрали длиной 7 км, отходящие от ТЭЦ, и по 5 ответвлений от каждой из этих основных магистралей, длиной по 3 км каждая, причем тепловая нагрузка как по основным магистралям, так и по ответвлениям распределяется равномерно.

Магистрали выполнены при подземной канальной прокладке. Их исходные диаметры были определены по расчетному расходу сетевой воды и оптимальной скорости ее течения при этом расходе. С учетом выбора из дискретного ряда они составили 600 мм для основных магистралей и 250 мм для ответвлений от магистралей для исходного температурного графика $150 / 70^{\circ} \mathrm{C}$ (рис. 1). При переходе на пониженные температурные графики оптимальные диаметры составили 700 мм и 300 мм для графика $130 / 70^{\circ} \mathrm{C}$ и 800 мм и 350 мм для графика $110 / 70^{\circ} \mathrm{C}$ (для основных магистралей и ответвлений от них соответственно).

С учетом того, что переход на пониженные температурные графики может производиться как при условии перекладки тепловых сетей от исходных диаметров 600 и 250 мм к их увеличенным значениям, так и без такой перекладки, расчеты затрат гидравлической энергии на транспортировку теплоносителя и нормативные тепловые потери в сетях были рассчитаны для всех трех вариантов диаметров тепловых сетей. 


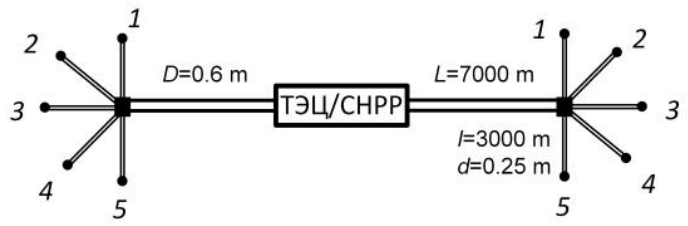

1-5 - ответвления от каждой из двух основных магистралей; $D, L$ - длина $u$ диаметр основной магистрали; $d, l$ - длина и диаметр каждого ответвления от основной магистрали

Рис. 1. Схема двухтрубной системы теплоснабжения исследуемой модельной ТЭЦ. ${ }^{1}$

Расчет производился при долях относительного расхода сетевой воды при смене способа регулирования при РГР, равных $20 \%$, $30 \%$ и $40 \%$, и с запасом мощности теплоносителя в системах отопления, равным $10 \%$ [14]. После расчета температурных графиков были определены минимальные значения расхода сетевой воды при смене способа регулирования при каждом исходном значении максимальной расчетной температуры прямой сетевой воды. Расчеты проводились поградусно по каждой целочисленной температуре наружного воздуха в отопительный период. Далее производилось определение интегральных за отопительный период характеристик с учетом длительности стояния температур в каждом одноградусном интервале [14].

Расчет гидравлических потерь в трубопроводах тепловых сетей производился по стандартной методике с учетом потерь по длине трубопроводов при известной скорости теплоносителя в каждом из них и потерь в местных сопротивлениях.

Требуемый напор сетевого насоса определялся для каждой температуры наружного воздуха по формуле (1), м:

$$
H_{\text {сн }}=\Delta H_{i s t}+\Delta H_{p o t r}+\Delta H_{p o d}+\Delta H_{o b r},
$$

где $\Delta H_{i s t}-$ потери напора в коммуникациях источника, приняты равными 25 м;

$\Delta H_{\text {potr }}$ - потери напора в местной системе теплопотребления, приняты равными $30 \mathrm{м}$;

$\Delta H_{p o d}$ и $\Delta H_{o b r}$ - гидравлические потери в подающем и обратном трубопроводах для каждой температуры наружного воздуха, м.

Затраты энергии на привод сетевых насосов ТЭЦ для сопоставления в рамках данного исследования за период длительностью $n$ рассчитывались по формуле (2), МВт·ч:

$$
N=(Q \cdot \rho \cdot H \cdot g \cdot n) / \eta
$$

где $Q$ - объемная подача насоса, $\mathrm{m}^{3} / \mathrm{c} ; H$ напор насоса, м; $\rho$ - плотность воды, принятая равной 1000 кг $/ \mathrm{M}^{3} ; g$ - ускорение свободного падения, равное $9.81 \mathrm{~m} / \mathrm{c}^{2} ; n$ - длительность периода, ч, $\eta-$ КПД сетевых насосов (принимался равным 0.8).

Для определения нормативных тепловых потерь в сетях использовалась методика, утвержденная Приказом Министерства энергетики РФ от 30 декабря 2008 г. № 325 "Об утверждении порядка определения нормативов технологических потерь при передаче тепловой энергии, теплоносителя". Расчет тепловых потерь производился для каждого графика ИТГ и РГР интегрально за отопительный период, при этом потери на всех участках тепловых сетей суммировались.

При выполнении исследования использовались следующие критерии для оценки эффективности работы системы теплоснабжения на основе паротурбинной ТЭЦ на пониженных температурных графиках. Основным параметром (критерием) энергетической эффективности является удельный расход условного топлива на единицу отпуска электрической энергии в сопоставимых условиях для сравниваемых вариантов. Последнее предполагает неизменность отпуска от ТЭЦ за рассматриваемый период (отопительный) как тепловой энергии, так и электрической энергии, с учетом изменения затрат электроэнергии на привод сетевых насосов, а также неизменность удельных затрат на отпуск тепловой энергии. Поэтому результаты по данному критерию существенно различаются для ТЭЦ, работающих при разных значениях коэффициента теплофикации. Расчеты произведены при использовании физического метода разделения затрат топлива по видам энергетической продукции, что в принятых граничных условиях обеспечивает выполнение всех условий сопоставления и корректность получаемых результатов.

Важными критериями сравнения при оптимизации параметров тепловых сетей являются величины затрат электроэнергии на транспортировку теплоносителя (привод сетевых насосов), величина нормативных теп- 
ловых потерь в сетях (и их доля в величине отпускаемой с ТЭЦ тепловой энергии) и сопоставление величин этих показателей с учетом затрат тепловой энергии на выработку потребляемой на собственные нужды ТЭЦ электроэнергии.

Величина удельной выработки электроэнергии на тепловом потреблении $Э_{m}$ в данном исследовании определялась для каждого режима работы турбоустановки для каждого исследуемого температурного графика по формулам, приведенным в статье («Расширенный график регулирования отопления: оценка влияния на эффективность паротурбинных ТЭЦ», Пятин А.А., Суворов Д.М. «Проблемы региональной энергетики», №3 (47), 2020, с. 40-55).

Интегральный удельный расход топлива на выработку электроэнергии, г у.т./кВт·ч, определен по известной формуле (3):

$$
b_{\text {ут }}^{\ni}=\frac{122.8 \cdot N_{э}}{\eta_{\mathrm{K}} \cdot \eta_{\mathrm{tp}} \cdot\left(\left(Q_{\mathrm{os}}+Q_{\text {ПВК }}\right)-Q_{\mathrm{T}}\right)},
$$

где $N_{э}$ - количество выработанной электроэнергии за весь отопительный период (интегрально), МВт·ч;

$\eta_{\text {к }}$ - КПД котла, принимаем 0.92;

$\eta_{\text {тр }}$ - КПД транспорта теплоты, принимаем 0,98 ;

$Q_{\text {os }}$ - затраты теплоты на турбоустановку за весь отопительный период, МВт·ч;

$Q_{\text {пвк }}$ - тепловая энергия, отпускаемая пиковыми водогрейными котлами, МВт·ч.

Интегральный удельный расход топлива на отпуск электроэнергии, г у.т./кВт·ч, определен по (4):

$$
b_{\mathrm{yт}}^{\text {эот }}=\frac{122.8 \cdot N_{\ni}^{\text {от }}}{\eta_{\mathrm{\kappa}} \cdot \eta_{\mathrm{Tp}} \cdot\left(\left(Q_{\mathrm{os}}+Q_{\mathrm{\Pi BK}}\right)-Q_{\mathrm{T}}\right)},
$$

где $N_{э}^{\text {от }}$ количество отпущенной электроэнергии за весь отопительный период, $\mathrm{MBT}$ ч.

Процент нормативных тепловых потерь, \%, рассчитан по формуле (5):

$$
\omega=100 \cdot \frac{Q_{\text {пот }}^{\mathrm{H}}}{Q_{\mathrm{T}}^{\text {TЭЦ }}}
$$

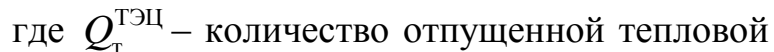
энергии от модельной ТЭЦ за период, МВт·ч;

$Q_{\text {пот }}^{\text {н }}-$ величина нормативных тепловых потерь в магистральных тепловых сетях за период, МВт·ч.

Дополнительно эффективность собственно теплоснабжения оценивалась также локальным (для определенной температуры) и интегральным (для всего отопительного периода) коэффициентом использования теплового потенциала теплоносителя $K_{m n}$, который рассчитывался по методике, приведенной в [14].

\section{СОПОСТАВИТЕЛЬНЫЕ РЕЗУЛЬТАТЫ ЭНЕРГЕТИЧЕСКОЙ ЭФФЕКТИВНОСТИ МОДЕЛЬНОЙ ТЭЦ ПРИ ПЕРЕХОДЕ НА ПОНИЖЕННЫЕ ТЕМПЕРАТУРНЫЕ ГРАФИКИ ПРИ НАЛИЧИИ И ПРИ ОТСУТСТВИИ РГР}

При расчете параметров регулирования при РГР важно определить наличие либо отсутствие ограничений по величине параметров РГР при переходе на пониженные температурные графики. С этой целью были просчитаны температурные графики абонентов отопления для РГР при варьировании доли расхода сетевой воды при смене способа регулирования при РГР от $20 \%$ до $40 \%$. Результаты расчетов представлены на рис. 2. Из них следует, что если при ИТГ 150/70 С минимальная величина доли расхода сетевой воды при смене способа регулирования при РГР составляет менее $20 \%$, то при ИТГ $130 / 70 \mathrm{C}$ она составляет уже около $30 \%$, и при ИТГ $110 / 70$ С уже составляет не менее $40 \%$. Таким образом, чем ниже температура прямой сетевой воды по исходному графику, тем при более низкой температуре наружного воздуха будет происходить смена способа регулирования при РГР. С другой стороны, реальная допустимая величина доли расхода сетевой воды при смене способа регулирования при РГР будет определяться при расчетноэкспериментальном исследовании конкретных абонентов, и следует ожидать, что в большинстве случаев она будет находиться на уровне $40 \%$ или даже несколько выше. Таким образом, полученные на рис. 2 результаты позволяют принять для сопоставления между собой как наиболее представительные результаты исследований РГР при доле расхода сетевой воды при смене способа регулирования $40 \%$, потому что они, с одной стороны, позволяют обеспечить работу при пони- 
женных по температуре прямой сетевой воды температурных графиках; с другой стороны, в наибольшей степени соответствуют условиям перехода на РГР реальных систем отопления.

Из графиков, представленных на рис. 2, следует, что во всем температурном диапазоне переход на РГР обеспечивает существенное снижение температуры обратной сетевой воды по сравнению с ИТГ, которое в области количественного регулирования отопления абонентов при РГР тем больше, чем меньше величина доли расхода при смене способа регулирования. Это снижение достигает $15-20^{\circ} \mathrm{C}$.

В то же время при заданной температуре воздуха в основной части отопительного периода по продолжительности, то есть в зоне от $+8^{\circ} \mathrm{C}$ до $-7^{\circ} \mathrm{C}$, где количественное регулирование отопления при РГР имеет место при всех принятых граничных условиях, это снижение вдвое больше при доле расхода при смене способа регулирования $20 \%$, нежели при его величине 40\%. Таким образом, именно в указанной зоне влияние наличия или отсутствия пониженного температурного графика на характер работы системы отопления при РГР выражено наиболее существенно, тогда как после перехода на работу с постоянной температурой $95^{\circ} \mathrm{C}$ и переменным расходом воды в системах отопления, то есть в области более низких температур воздуха, такое влияние практически отсутствует (рис. 2).

На рис. 3 представлены расходы сетевой воды в модельной системе теплоснабжения при наличии и при отсутствии РГР при различных ИТГ. Очевидно, что при РГР они в течение основной части отопительного периода существенно ниже, чем при ИТГ.

Гидравлические потери для РГР при доле расхода сетевой воды при смене способа регулирования $40 \%$ в зависимости от температур наружного воздуха представлены на рис. 4.

При соответствующих ИТГ эти потери не зависят от температуры воздуха и несколько выше, чем максимальные потери при РГР (при температурах ниже $-33^{\circ} \mathrm{C}$. Из графиков, приведенных на рис. 4, следует, что в основной части времени отопительного периода (до смены способа регулирования, имеющем место при $\left.-24^{\circ} \mathrm{C}\right)$, потери при РГР почти в 2 раза ниже, чем при ИТГ, что связано с существенно меньшими расходами сетевой воды. Также можно сделать вывод, что при перехо- де на пониженные графики гидравлические потери при исходных диаметрах тепловых сетей существенно возрастают, причем при переходе на график $110 / 70^{\circ} \mathrm{C}$ - более, чем в 3 раза по сравнению с графиком $150 / 70^{\circ} \mathrm{C}$.

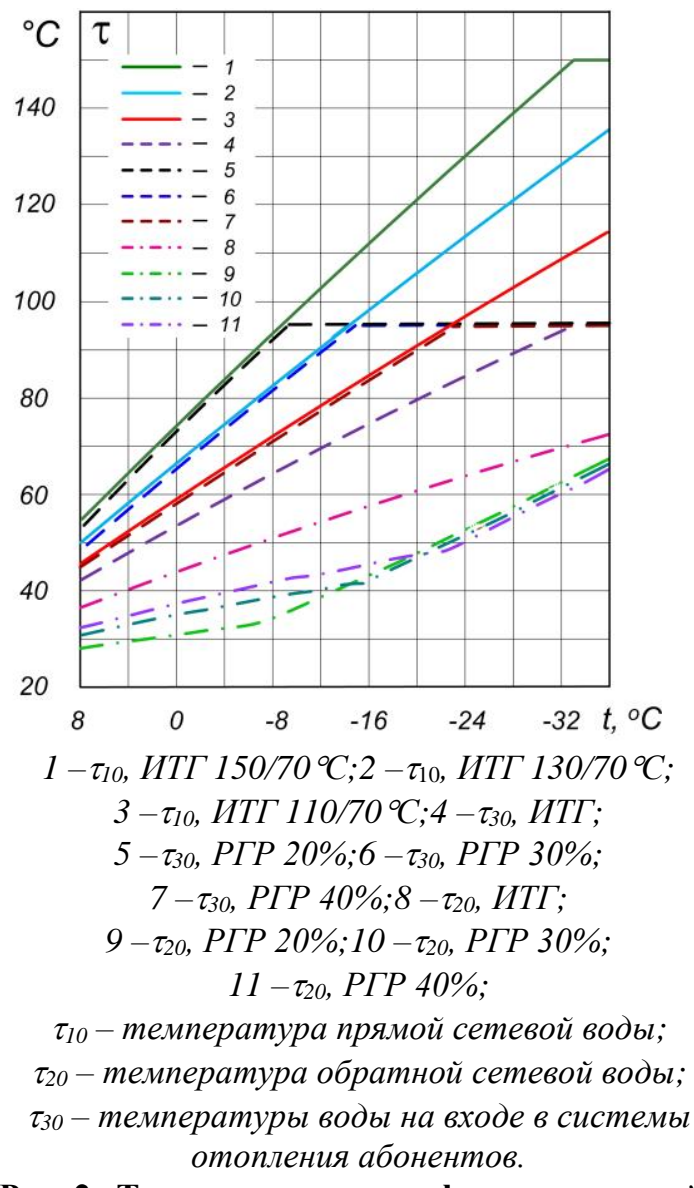

Рис. 2. Температурные графики модельной системы теплоснабжения и модельной ТЭЦ при ИТГ $150 / 70^{\circ} \mathrm{C}, 130 / 70^{\circ} \mathrm{C}$ и $110 / 70^{\circ} \mathrm{C}$, а также при соответствующих им РГР. В процентах указана доля расхода сетевой воды при смене способа регулирования при РГР.2

Вычисленный интегрально за отопительный период с использованием формулы (2) расход электроэнергии на привод сетевых насосов при ИТГ и при РГР с долей расхода сетевой воды при смене способа регулирования $40 \%$ представлен в таблице 1.

По представленным результатам можно сделать вывод, что при увеличении диаметра трубопроводов потребляемая мощность существенно сокращается. Однако при переходе на пониженные температурные графики (как ИТГ, так и РГР) даже при максимальных допустимых диаметрах (700 мм при $130^{\circ} \mathrm{C}$ и 800 мм при $110^{\circ} \mathrm{C}$ ) расход электроэнергии оказывается все равно существенно выше, чем при графиках с максимальной темпера- 
турой $150^{\circ} \mathrm{C}$. Также можно сделать вывод, что потребляемая мощность при РГР при долях расхода сетевой воды от 20 до 40\% по сравнению с графиками ИТГ существенно сокращается (от 13 до 58\%). Исходя из затрат мощности на привод сетевых насосов, можно сделать вывод о том, что эффективность перехода на пониженные температурные графики не очевидна.

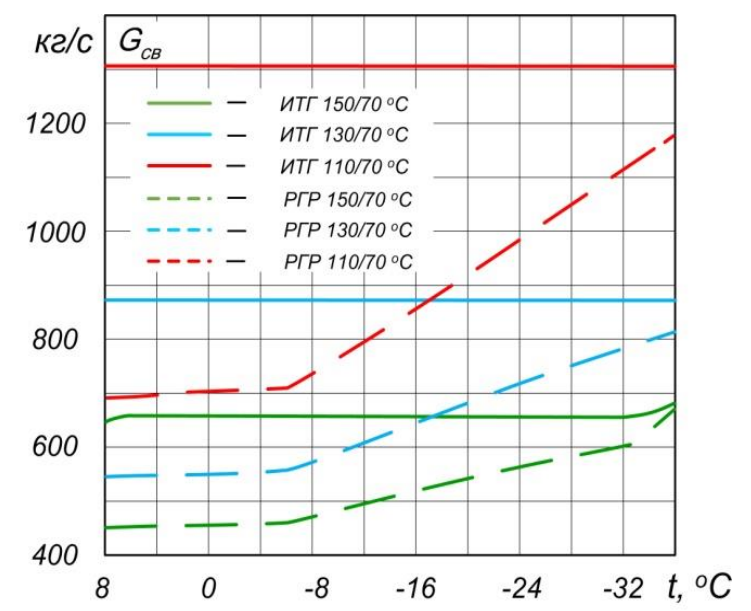

Рис. 3. Расходы сетевой воды на ТЭЦ при наличии и при отсутствии РГР при исходных и пониженных температурных графиках. ${ }^{3}$

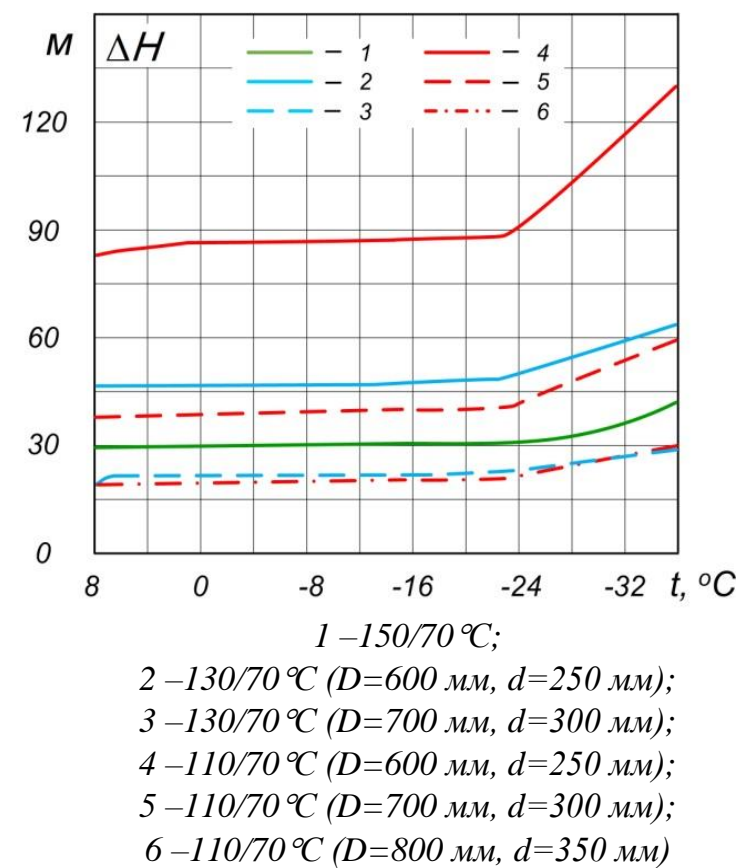

Рис. 4. Гидравлические потери графиков РГР при доле расхода сетевой воды 40\%.

Результаты расчета нормативных тепловых потерь в сетях, вычисленных по общепринятой методике с учетом потерь через тепловую изоляцию, с потерями и утечками теплоносителя на пусковое заполнение тру- бопроводов (один раз за отопительный сезон) приведены в таблице 2.

Исходя из результатов этих расчетов, можно сделать вывод, что величина нормативных тепловых потерь существенно зависит от диаметра трубопроводов, и при увеличении диаметров при переходе на пониженные графики эти потери увеличиваются на $13 \%$ при переходе на диаметр 700 мм и на $28 \%$ при переходе на диаметр 800 мм (несмотря на снижение максимальной температуры теплоносителя). При переходе от ИТГ $150 / 70^{\circ} \mathrm{C}$ на пониженные графики $130 / 70^{\circ} \mathrm{C}$ и $110 / 70^{\circ} \mathrm{C}$ без реконструкции трубопроводов тепловые потери уменьшаются, в среднем, на $7-8 \%$, что соответствует данным $[1,3]$, но что следует признать несущественным, так как это снижение потерь в несколько раз меньше, чем дополнительный расход электроэнергии на привод сетевых насосов, определенный в тех же условиях и в таких же единицах измерения (табл. 1). В то же время при реконструкции трубопроводов тепловые потери увеличиваются на 14-27\%. При переходе от ИТГ на РГР тепловые потери уменьшаются, в среднем, на 5-6\%, что говорит о преимуществе РГР перед ИТГ и по данному параметру эффективности.

В результате совместного рассмотрения таких параметров эффективности, как затраты электроэнергии на привод сетевых насосов и нормативные тепловые потери в тепловых сетях, можно сделать общий вывод, что переход с ИТГ на РГР во всех случаях дает существенное преимущество, прежде всего по экономии электроэнергии на привод сетевых насосов, а вот переход на пониженные температурные графики является неэффективным как при сохранении исходных диаметров трубопроводов тепловых сетей (в этом случае в несколько раз увеличиваются затраты электроэнергии на привод сетевых насосов, которые лишь в малой степени компенсируются сокращением нормативных тепловых потерь в сетях), так и при переходе на повышенные диаметры трубопроводов. Применительно к крупным районным котельным, не имеющим выработки электроэнергии, данные выводы показывают энергетическую неэффективность перехода с проектных на пониженные температурные графики для подключенных к ним систем теплоснабжения, а также высокую эффективность перехода систем теплоснабжения с ИТГ на РГР. Что касается ТЭЦ, то для них следует дополнитель- 
но учитывать показатели эффективности выработки электроэнергии при характерных граничных условиях сопоставления.

Интегральные показатели эффективности всех рассчитанных графиков по режимам работы ТЭЦ за отопительный период, определенные по формулам (2-5), представлены далее в виде таблиц 3 и 4 раздельно для коэффициентов теплофикации 0.5 и 1.0. Применительно к РГР данные приведены только при доле расхода сетевой воды при смене способа регулирования для РГР 40\%, так как такая величина данного показателя возможна и при пониженных температурных графиках, и она наиболее вероятна по свойствам систем отопления абонентов, чем его значения 30 и $20 \%$.

Анализируя данные таблиц 3 и 4, можно прийти к следующим заключениям.

1. При работе ТЭЦ с близким к проектному значению коэффициента теплофикации 0.5 наиболее эффективным для ИТГ по величине удельного расхода условного топлива на отпуск электроэнергии является график $130 / 70^{\circ} \mathrm{C}$ при диаметре магистрального трубопровода 700 мм. Что касается РГР, то для него является более эффективным график с переходом к максимальной температуре теплоносителя $110^{\circ} \mathrm{C}$ и диаметре трубопровода 800 мм.

2. Работа ТЭЦ с коэффициентом теплофикации 1.0 характерна при условии снижения тепловых нагрузок в 1.5-2 раза по отношению к проектным. В этих условиях ТЭЦ в течение практически всего отопительного периода будет иметь наилучшие показатели эффективности при переходе на температурный график с максимальной температурой теплоносителя $110^{\circ} \mathrm{C}$.

3. Величина снижения удельного расхода топлива на отпуск электроэнергии обусловлена совместным действием двух факторов увеличения удельной выработки электроэнергии на тепловом потреблении $Э_{m}$ и увеличения затрат электроэнергии на привод сетевых насосов при переходе на пониженные температурные графики. При этом следует учесть, что при диаметре трубопровода 800 мм имеют место и самые большие нормативные тепловые потери, достигающие почти $8 \%$ от отпуска тепловой энергии в сеть.

Таблица $1^{5}$.

Расход электроэнергии на привод сетевых насосов за отопительный период, МВт·ч, для температурных графиков ИТГ и РГР с долей расхода сетевой воды при смене способа регулирования $40 \%$ при различных диаметрах трубопроводов и максимальных температурах сетевой воды ${ }^{6}$

\begin{tabular}{|l|l|l|l|l|l|l|}
\hline$\tau,{ }^{\circ} \mathrm{C}$, & 150 & 130 & 130 & 110 & 110 & 110 \\
$/ \mathrm{d}$, мм (mm) & $/ 600$ & $/ 600$ & $/ 70$ & $/ 600$ & $/ 700$ & $/ 800$ \\
\hline ИТГ (ITS) & 3759 & 6147 & 4398 & 16937 & 9378 & 6943 \\
\hline РГР (ERS) & 2532 & 5149 & 3850 & 7156 & 4753 & 3776 \\
\hline
\end{tabular}

Таблица $2^{7}$. Нормативные тепловые потери для температурных графиков ИТГ и РГР с долей расхода сетевой воды при смене способа регулирования $40 \% 8$

\begin{tabular}{|l|l|l|}
\hline & \multicolumn{2}{|l|}{$\begin{array}{l}Q_{\text {пот }}^{\mathrm{H}}, \text { МВт·ч/год } \\
\left(Q_{\text {loss }}^{\mathrm{s}}, \mathrm{MW} \cdot \mathrm{h} / \mathrm{year}\right)\end{array}$} \\
\hline $\begin{array}{l}\text { температура }{ }^{\circ} \mathrm{C}, \\
\text { /диаметр, } \\
\text { (temperature } \\
{ }^{\circ} \mathrm{C}, / \\
\text { diameter, } \mathrm{mm})\end{array}$ & ИТГ(ITS) & РГР (ERS) \\
\hline $150 / 600$ & 35874 & 34509 \\
\hline $130 / 600$ & 34295 & 32803 \\
\hline $130 / 700$ & 40763 & 38967 \\
\hline $110 / 600$ & 32356 & 30892 \\
\hline $110 / 700$ & 38434 & 36671 \\
\hline $110 / 800$ & 45743 & 43634 \\
\hline
\end{tabular}


Таблица $3^{9}$.

Интегральные показатели исследуемых графиков при коэффициенте теплофикации 0.5 различных диаметрах трубопроводов и максимальных температурах сетевой воды при доле расхода сетевой воды при смене способа регулирования для РГР $40 \%{ }^{10}$

\begin{tabular}{|c|c|c|c|c|c|}
\hline $\begin{array}{l}\text { Вид графика, макси- } \\
\text { мальная температура, } \\
{ }^{\circ} \mathrm{C} / \text { диаметр, мм } \\
\text { (Schedule type, maxi- } \\
\text { mum temperature, }{ }^{\circ} \mathrm{C} / \\
\text { diameter, mm) }\end{array}$ & $\begin{array}{l}\ni_{m} \\
(E)\end{array}$ & $\begin{array}{c}b_{\mathrm{yт}}^{\ni}, \text { г у.т./кВт॰ч } \\
\left(b_{\mathrm{cf}}^{\mathrm{e}}, \mathrm{g} \text { c.f./ }\right. \\
\mathrm{kW} \cdot \mathrm{h})\end{array}$ & $\begin{array}{c}b_{\text {ут }}^{\text {эот }}, \text { Г } \\
\text { y.т./КВт॰ч } \\
\left(b_{\mathrm{cf}}^{\text {eh }}, \mathrm{g} \mathrm{c.f./}\right. \\
\mathrm{kW} \cdot \mathrm{h})\end{array}$ & $\begin{array}{c}K_{\mathrm{tп}} \\
\left(K_{\mathrm{hl}}\right)\end{array}$ & $\omega, \%$ \\
\hline $\begin{array}{l}\text { ИТГ } 150 / 600 \\
\text { (IТS } 150 / 600)\end{array}$ & 0.498 & 195.1 & 197.3 & 0.569 & 6.10 \\
\hline $\begin{array}{l}\text { ИТГ 130/600 } \\
\text { (ITS 130/600) }\end{array}$ & \multirow{2}{*}{0.507} & 192.9 & 196.5 & \multirow{2}{*}{0.497} & 5.83 \\
\hline $\begin{array}{l}\text { ИТГ 130/700 } \\
\text { (ITS 130/700) }\end{array}$ & & 192.9 & 195.5 & & 6.93 \\
\hline $\begin{array}{l}\text { ИТГ } 110 / 600 \\
\text { (ITS 110/600) }\end{array}$ & \multirow{3}{*}{0.507} & 192.9 & 203.3 & \multirow{3}{*}{0.398} & 5.50 \\
\hline $\begin{array}{l}\text { ИТГ } 110 / 700 \\
\text { (ITS } 110 / 700)\end{array}$ & & 192.9 & 198.5 & & 6.54 \\
\hline $\begin{array}{l}\text { ИТГ } 110 / 800 \\
\text { (ITS } 110 / 800)\end{array}$ & & 192.9 & 197.0 & & 7.78 \\
\hline $\begin{array}{l}\text { РГР } 150 / 600 \\
\text { (ERS 150/600) }\end{array}$ & 0.504 & 193.5 & 195.0 & 0.696 & 5.84 \\
\hline $\begin{array}{l}\text { PГР130/600 } \\
\text { (ERS 130/600) }\end{array}$ & \multirow{2}{*}{0.513} & 191.7 & 194.7 & \multirow{2}{*}{0.645} & 5.55 \\
\hline $\begin{array}{l}\text { РГР 130/700 } \\
\text { (ERS 130/700) }\end{array}$ & & 191.7 & 193.9 & & 6.59 \\
\hline $\begin{array}{l}\text { PГР 110/600 } \\
\text { (ERS 110/600) }\end{array}$ & \multirow{3}{*}{0.516} & 191.0 & 195.2 & \multirow{3}{*}{0.575} & 5.23 \\
\hline $\begin{array}{l}\text { РГР 110/700 } \\
\text { (ERS 110/700) }\end{array}$ & & 191.0 & 193.8 & & 6.59 \\
\hline $\begin{array}{l}\text { РГР 110/ 800 } \\
(\text { ERS 110/800) }\end{array}$ & & 191.0 & 193.2 & & 7.38 \\
\hline
\end{tabular}

4. При отсутствии изменения диаметров трубопроводов тепловых сетей переход ТЭЦ на пониженные против исходного при $150^{\circ} \mathrm{C}$ температурные графики и одновременно на РГР является вполне эффективными обеспечивает экономию по величине удельного расхода условного топлива на отпуск электроэнергии до $1.3 \%$ при коэффициенте теплофикации 0.5 (при максимальной температуре $130^{\circ} \mathrm{C}$ ) и до $2.0 \%$ при коэффициенте теплофикации 1.0 (при максимальной температуре $110^{\circ} \mathrm{C}$ ).

5. При переходе от ИТГ на РГР величина коэффициента использования теплового потенциала теплоносителя существенно возрастает.

Интегральным топливным показателем эффективности перехода на РГР при различных максимальных температурах является также годовая экономия теплоты топлива за год (в данном случае за отопительный пери- од). Результаты расчета годовой экономии теплоты топлива при переходе к пониженным температурным графикам и к РГР, определенные в относительном виде (по отношению к суммарным затратам теплоты топлива на ТЭЦ), полностью соответствуют результатам изменения интегральных удельных затрат условного топлива на отпуск электроэнергии, приведенных в табл. 3 и 4, и поэтому отдельно не приводятся. Но это соответствие свидетельствует о правильности как принятых для сопоставления граничных условий, так и выполненных расчетов.

Таким образом, если речь идет о работе с исходными диаметрами теплопроводов 600 мм, то среди ИТГ наилучшим является при обеих значениях $\alpha=0.5$ и $\alpha=1.0$ температурный график $130 / 70^{\circ} \mathrm{C}$, а при переходе к РГР график $110 / 70^{\circ} \mathrm{C}$ получает преимущество 
только при $\alpha=1.0$, то есть когда тепловая нагрузка ТЭЦ намного ниже, чем проектная расчетная нагрузка.

Переход на пониженные по температурам прямой и обратной сетевой воды температурные графики приводит к некоторому увеличению выработки электроэнергии на тепловом потреблении. Ранее в работе («Расширенный график регулирования отопления: оценка влияния на эффективность паротурбинных ТЭЦ», Пятин А.А., Суворов Д.М.
«Проблемы региональной энергетики», №3 (47), 2020, с. 40-55) авторами было показано, что при переходе на РГР снижение температуры обратной сетевой воды приводит к значительному росту $Э_{m}$ (на 4-6\%) только при работе агрегатов ТЭЦ по тепловому графику. Эти выводы в целом подтверждаются результатами данного исследования, представленными на рис. 5,7 (для $\alpha=0.5$ ) и на рис. 6,8 (для $\alpha=1$ ), но они требуют дополнительных комментариев.

Таблица $4^{11}$.

Интегральные показатели исследуемых графиков при коэффициенте теплофикации 1.0 различных диаметрах трубопроводов и максимальных температурах сетевой воды при доле расхода сетевой воды при смене способа регулирования для РГР 40\% ${ }^{12}$

\begin{tabular}{|c|c|c|c|c|c|}
\hline $\begin{array}{l}\text { Вид графика, мак- } \\
\text { симальная темпе- } \\
\text { ратура, }{ }^{\circ} \mathrm{C} \\
\text { /диаметр, мм } \\
\text { (Schedule type, } \\
\text { maximum tempera- } \\
\text { ture, }{ }^{\circ} \mathrm{C} / \text { diameter, } \\
\text { mm) }\end{array}$ & $\begin{array}{l}\ni_{m} \\
(E)\end{array}$ & $\begin{array}{c}b_{\text {ут }}^{\ni}, \Gamma \\
\text { у.т./КВТ'ч } \\
\left(b_{\mathrm{cf}}^{\mathrm{e}}, \mathrm{g} \mathrm{c.f./}\right. \\
\mathrm{kW} \cdot \mathrm{h})\end{array}$ & $\begin{array}{c}b_{\text {ут }}^{\text {эот }}, \text { г у.т./кВт·ч } \\
\left(b_{\text {cf }}^{\text {eh }}, \text { g c.f./ }\right. \\
\mathrm{kW} \cdot \mathrm{h})\end{array}$ & $\begin{array}{c}K_{\text {тп }} \\
\left(K_{\mathrm{hl}}\right)\end{array}$ & $\omega, \%$ \\
\hline $\begin{array}{l}\text { ИТГ 150/600 } \\
\text { (ITS 150/600) }\end{array}$ & 0.491 & 274.1 & 275.6 & 0.569 & 6.10 \\
\hline $\begin{array}{l}\text { ИТГ 130/600 } \\
\text { (ITS 130/600) }\end{array}$ & \multirow{2}{*}{0.501} & 269.8 & 272.2 & \multirow{2}{*}{0.497} & 5.83 \\
\hline $\begin{array}{l}\text { ИТГ 130/700 } \\
\text { (ITS 130/700) }\end{array}$ & & 269.8 & 271.5 & & 6.93 \\
\hline $\begin{array}{l}\text { ИТГ 110/600 } \\
\text { (ITS 110/600) }\end{array}$ & \multirow{3}{*}{0.509} & 267.8 & 274.4 & \multirow{3}{*}{0.398} & 5.50 \\
\hline $\begin{array}{l}\text { ИТГ 110/700 } \\
\text { (ITS 110/700) }\end{array}$ & & 267.8 & 271.4 & & 6.54 \\
\hline $\begin{array}{l}\text { ИТГ 110/800 } \\
\text { (ITS 110/800) }\end{array}$ & & 267.8 & 270.5 & & 7.78 \\
\hline $\begin{array}{l}\text { РГР 150/600 } \\
\text { (ERS 150/600) }\end{array}$ & 0.494 & 273.3 & 274.3 & 0.696 & 5.84 \\
\hline $\begin{array}{l}\text { РГР 130/600 } \\
\text { (ERS 130/600) }\end{array}$ & \multirow{2}{*}{0.504} & 269.3 & 271.3 & \multirow{2}{*}{0.645} & 5.55 \\
\hline $\begin{array}{l}\text { РГР 130/700 } \\
\text { (ERS 130/700) }\end{array}$ & & 269.3 & 270.8 & & 6.59 \\
\hline $\begin{array}{l}\text { РГР 110/ 600 } \\
\text { (ERS 110/600) }\end{array}$ & \multirow{3}{*}{0.511} & 267.3 & 270.0 & \multirow{3}{*}{0.575} & 5.23 \\
\hline $\begin{array}{l}\text { РГР 110/ 700 } \\
\text { (ERS 110/700) }\end{array}$ & & 267.3 & 269.1 & & 6.59 \\
\hline $\begin{array}{l}\text { РГР 110/ 800 } \\
\text { (ERS 110/800) }\end{array}$ & & 267.3 & 268.7 & & 7.38 \\
\hline
\end{tabular}




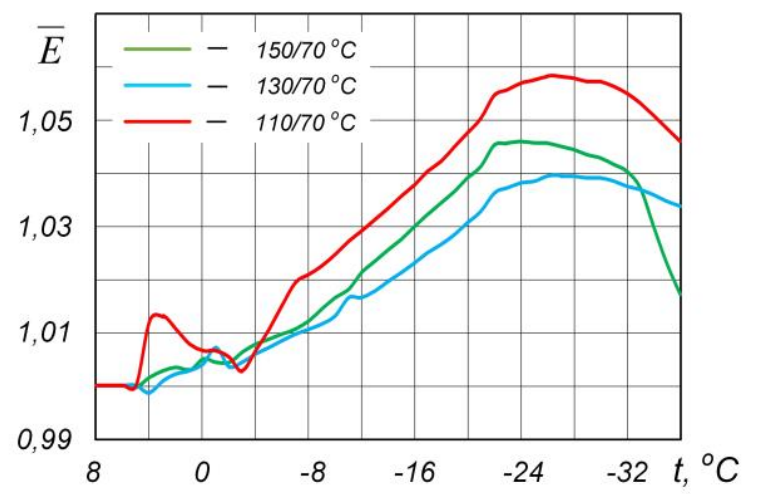

Рис. 5. Отношение удельной выработки электроэнергии на тепловом потреблении при РГР к ИТГ при коэффициенте теплофикации $\alpha=0.5$. Доля расхода сетевой воды при смене способа регулирования $40 \% .^{13}$

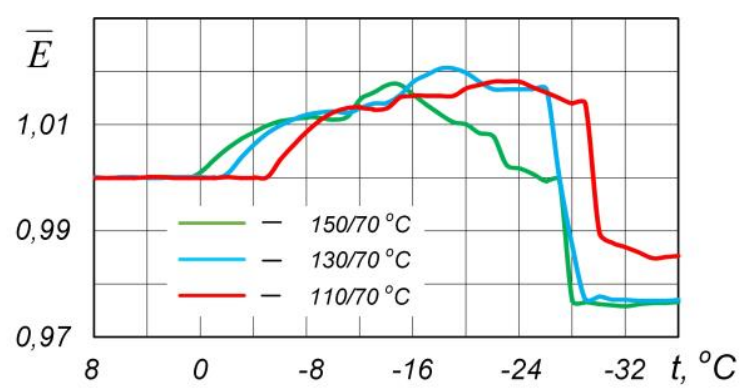

Рис. 6. Отношение удельной выработки электроэнергии на тепловом потреблении при РГР к ИТГ при коэффициенте теплофикации $\alpha=1.0$. Доля расхода сетевой воды при смене способа регулирования $40 \% .^{14}$

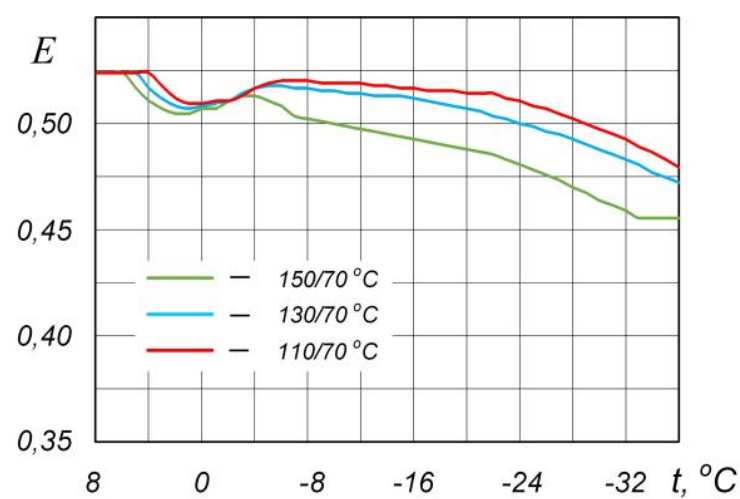

Рис. 7. Удельная выработка электроэнергии на тепловом потреблении $E$ при РГР с долей расхода сетевой воды при смене способа регулирования $40 \%$ при $\alpha=0.5 .15$

Во-первых, следует отметить величину увеличения среднеинтегральной величины $Э_{m}$ при переходе с исходного на пониженные температурные графики. Это увеличение при $\alpha=1.0$ составляет $2 \%$ при переходе с графика $150 / 70^{\circ} \mathrm{C}$ на график $130 / 70^{\circ} \mathrm{C}$ и $3.7 \%$ при переходе с графика $150 / 70^{\circ} \mathrm{C}$ на график $110 / 70^{\circ} \mathrm{C}$ (табл. 4). Аналогичные показатели при $\alpha=0.5$ равны $1.8 \%$ при переходе с графика $150 / 70^{\circ}$ Скак на график $130 / 70^{\circ} \mathrm{C}$, так и на график $110 / 70^{\circ} \mathrm{C}$. Это равенство приростов в последнем случае имеет место потому, что при $\alpha=0.5$, когда на модельной ТЭЦ работает только одна турбоустановка, расход сетевой воды как при графике $130 / 70^{\circ} \mathrm{C}$, так и при графике $110 / 70^{\circ} \mathrm{C}$ в течение всего отопительного периода превышает максимально допустимый для сетевой подогревательной установки турбины Т-50-12.8 расход, составляющий 833 кг/с.

Таким образом, при повышенных расходах сетевой воды на ТЭЦ, возникающих при переходе на пониженные температурные графики при отсутствии РГР, снижение максимальной расчетной температуры сетевой воды ниже определенного уровня (в данном случае это примерно $130^{\circ} \mathrm{C}$ ) не дает преимуществ с точки зрения дополнительной выработки электроэнергии.

Во-вторых, переход на РГР дает существенное увеличение выработки электроэнергии только в области работы по тепловому графику с максимальной тепловой нагрузкой отборов турбин, то есть при $\alpha=0.5$ при температуре наружного воздуха минус $7^{\circ} \mathrm{C}$ и ниже (рис. 5), и влияние этого увеличения на интегральные показатели работы ТЭЦ невелико.

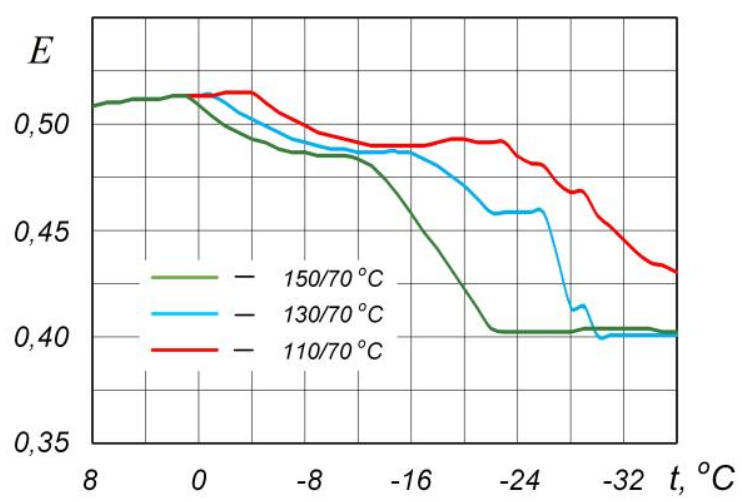

Рис. 8. Удельная выработка электроэнергии на тепловом потреблении $E$ при РГР с долей расхода сетевой воды при смене способа регулирования 40\% при $\alpha=1.0 .{ }^{16}$

Важно отметить, что основной причиной того, что линия графика при максимальной температуре теплоносителя $110^{\circ} \mathrm{C}$ идет на рис. 5 выше, чем при $130^{\circ} \mathrm{C}$, является то, что ИТГ при обеих этих максимальных температурах одинаковы, а РГР при $110^{\circ} \mathrm{C}$ имеет более высокие значения $Э_{m}$ (рис. 7).

Существенно, что график отношения удельной выработки электроэнергии на теп- 
ловом потреблении для РГР при доле расхода $40 \%$ к ИТГ при коэффициенте теплофикации 1 (рис. 6) имеет при высоких температурах наружного воздуха горизонтальный участок, где данное отношение равно 1. Наличие такого горизонтального участка имеет место потому, что в этих вариантах турбоустановки ТЭЦ работают в одинаковых режимах по выработке электроэнергии, потому что их РД ЧНД полностью открыты, задвижки на верхние сетевые подогреватели полностью закрыты, а регулирование тепловой нагрузки осуществляется прикрытием паровых задвижек на нижние сетевые подогреватели турбин (либо их обводом по сетевой воде), что и приводит к одинаковым давлениям в отопительных отборах и одинаковым расходам пара в конденсатор и на нижние сетевые подогреватели. Это подтверждает и рис. 8, где в левой части графика все 3 линии сливаются.

В данной работе были также рассчитаны показатели экономической эффективности перехода на пониженные температурные графики при условии перекладки трубопроводов тепловых сетей с исходных 600 мм (для основных тепломагистралей) на энергетически оптимальные $\left(700\right.$ мм для ИТГ $130 / 70^{\circ} \mathrm{C}$ и 800 мм для ИТГ $\left.110 / 70^{\circ} \mathrm{C}\right)$. Учитывалось как изменение отпуска электроэнергии с ТЭЦ, определенное ранее, так и капитальные затраты, связанные с перекладкой основных магистралей и ответвлений от них на трубопроводы повышенных диаметров.

В результате расчета был определен простой срок окупаемости капитальных затрат в эту перекладку с использованием фактических цен 2021 года в России с учетом экономии затрат топлива. Результаты этих расчетов показали, что для $\alpha=0.5$ срок окупаемости капитальных затрат составляет 49 лет и более, а для $\alpha=1.0$ он составляет 23 года при переходе на график $130 / 70^{\circ} \mathrm{C}$ и 32 года при переходе на график $110 / 70^{\circ} \mathrm{C}$. Такие большие сроки являются инвестиционно неприемлемыми.

Таким образом, повышенные диаметры трубопроводов, обеспечивающие наивысшую энергетическую эффективность температурных графиков с пониженной температурой прямой сетевой воды, следует использовать не при перекладке в ходе реконструкции систем теплоснабжения, а при исходном проектировании и строительстве этих систем для условий проектных пониженных температурных графиков. Но и тогда эффективность их применения подлежит дополнительному экономическому обоснованию.

\section{ЗАКЛЮЧЕНИЕ}

1. К показателям, которые характеризуют эффективность работы ТЭЦ при анализе их работы при различных температурных графиках, следует отнести удельные показатели по расходу топлива на выпуск энергетической продукции в сопоставимых условиях (в данном случае, при использовании физического метода, это удельный расход условного топлива на отпуск электрической энергии), расход натурального либо условного топлива (или теплоты топлива) на обеспечение заданного графика отпуска электрической и тепловой энергии, удельную выработку электроэнергии на тепловом потреблении $Э_{m}$, общие и удельные затраты электроэнергии на привод сетевых насосов, величину и долю нормативных потерь тепловой энергии в тепловых сетях, а также коэффициент использования теплового потенциала теплоносителя $K_{m n}$.

2. При РГР основным параметром, ограничивающим эффективность перехода на пониженные температурные графики, является минимально допустимая доля расхода сетевой воды для абонентов при смене способа регулирования. Установлено, что при графике с максимальной температурой сетевой воды $150^{\circ} \mathrm{C}$ (без учета возможной срезки) эта доля составляет не менее $20 \%$, при графике с максимальной температурой сетевой воды $130^{\circ} \mathrm{C}$ - не менее $30 \%$, а при графике с максимальной температурой сетевой воды $110^{\circ} \mathrm{C}$ - не менее $40 \%$.

3. Переход систем теплоснабжения со стандартного на пониженный температурный график, как при ИТГ, так и при РГР, с точки минимизации энергетических затрат с учетом расхода электроэнергии на привод сетевых насосов и нормативных тепловых потерь в магистральных тепловых сетях, если он определяется без учета изменения эффективности выработки электроэнергии, не является целесообразным. Для всех расчетных режимов дополнительные затраты теплоты топлива на ТЭЦ, связанные с увеличением расхода электроэнергии на привод сетевых насосов, в несколько раз превосходят экономию от снижения нормативных тепловых потерь в сетях. Поэтому для крупных котельных переход на пониженные непроектные температурные графики является энергетически неэффективным. 
4. Несмотря на то, что за счет увеличения выработки электроэнергии на тепловом потреблении ТЭЦ при работе на пониженных температурных графиках с реконструкцией тепловых сетей путем перехода на увеличенные диаметры трубопроводов тепломагистралей достигается минимальная величина удельного расхода условного топлива на отпускаемую электрическую энергию, такая реконструкция является экономически нецелесообразной, поскольку сроки ее окупаемости при всех вариантах граничных условий составляют не менее 23 лет.

5. С точки зрения удельного расхода теплоты на отпуск электроэнергии при ИТГ для любого коэффициента теплофикации оптимальным является температурный график $130 / 70^{\circ} \mathrm{C}$, а при РГР для коэффициента теплофикации 0.5 наилучшим также является график с максимальной температурой сетевой воды $130^{\circ} \mathrm{C}$, а для коэффициента теплофикации 1.0 - температурный график с максимальной температурой сетевой воды $110^{\circ} \mathrm{C}$. Таким образом, переход температурный график с максимальной температурой сетевой воды $110^{\circ} \mathrm{C}$ при наличии РГР может быть энергетически целесообразен только для ТЭЦ, имеющих небольшие относительные тепловые нагрузки и работающих по электрическому графику вплоть до предельно низких температур воздуха.

6. Среднеинтегральная величина удельной выработки электроэнергии на тепловом потреблении для коэффициента теплофикации 0.5 при понижении температурного графика с $150 / 70^{\circ} \mathrm{C}$ до $110 / 70^{\circ} \mathrm{C}$ как при ИТГ, так и при РГР увеличивается, в среднем, на $2 \%$, а для коэффициента теплофикации 1.0 - на $3.5 \%$; при этом переход от ИТГ на РГР при том же верхнем значении температуры графика дает прирост этой величины не более $1.6 \%$ для коэффициента теплофикации 0.5 , и не более $0.8 \%$ - для коэффициента теплофикации 1.0.

7. Интегральная эффективность РГР в незначительной степени зависит от доли расхода сетевой воды при смене способа регулирования, в процентах от расчетного. Так, удельный расход теплоты на отпуск электроэнергии при увеличении данного показателя с $20 \%$ до $40 \%$ возрастает не более чем на $0.7 \%$ при любом значении коэффициента теплофикации.

8. Среднегодовой коэффициент использования теплового потенциала теплоносителя существенно понижается при переходе на пониженные температурные графики, что связано с методикой его определения. При переходе от ИТГ на РГР величина данного показателя существенно возрастает. Таким образом, данный показатель не является универсальным и может использоваться для характеристики эффективности работы систем теплоснабжения только в сочетании с максимальной температурой теплоносителя, имеющей место при использовании того или иного температурного графика.

\section{APPENDIX1 (ПРИЛОЖЕНИЕ 1)}

${ }^{1}$ Fig. 1. Diagram of a two-pipe heat supply system of the investigated model CHPP.(1-5 - branches from each of the two main heat pipelines; D, L - length and diameter of the main line; $d, 1$ - length and diameter of each branch from the main line).

${ }^{2}$ Fig. 2. Temperature schedule of the model heat supply system and the model CHPP with the ITS $150 / 70^{\circ} \mathrm{C}, 130 / 70^{\circ} \mathrm{C}$ and $110 / 70^{\circ} \mathrm{C}$, as well as with the corresponding ERS. The share of the flow rate of the delivery water when the regulation method changing in using the ERS is indicated as a percentage. (1$\tau_{10}$, ITS $150 / 70^{\circ} \mathrm{C} ; 2-\tau_{10}$, ITS $130 / 70^{\circ} \mathrm{C} ; 3-\tau_{10}$, ITS $110 / 70^{\circ} \mathrm{C} ; 4-\tau_{30}$, ITS; $5-\tau_{30}$, ERS $20 \% ; 6-\tau_{30}$, ERS $30 \% ; 7-\tau_{30}$, ERS $40 \% ; 8-\tau_{20}$, ITS; $9-\tau_{20}$, ERS $20 \% ; 10-\tau_{20}$, ERS $30 \% ; 11-\tau_{20}$, ERS $40 \%$; $\tau_{01}$ is the supply water temperature; $\tau_{20}$ is the return water temperature, $\tau_{30}$ is the water temperature at the inlet to the users' heating systems).

${ }^{3}$ Fig. 3. The delivery water flow rate at CHPP with ERS and without ERS with the initial and decreased temperature schedules.

${ }^{4}$ Fig. 4. Hydraulic losses of the ERS schedules with a $40 \%$ share of the flow rate of delivery water when the regulation method changing. $\left(1-150 / 70^{\circ} \mathrm{C} ; 2\right.$ $130 / 70^{\circ} \mathrm{C}(\mathrm{D}=600 \mathrm{~mm}, \mathrm{~d}=250 \mathrm{~mm}) ; 3-130 / 70^{\circ} \mathrm{C}$ $(\mathrm{D}=700 \mathrm{~mm}, \mathrm{~d}=300 \mathrm{~mm}) ; 4-110 / 70^{\circ} \mathrm{C}(\mathrm{D}=600 \mathrm{~mm}$, $\mathrm{d}=250 \mathrm{~mm}) ; 5-110 / 70^{\circ} \mathrm{C}(\mathrm{D}=700 \mathrm{~mm}, \mathrm{~d}=300 \mathrm{~mm}) ; 6$ $\left.-110 / 70^{\circ} \mathrm{C}(\mathrm{D}=800 \mathrm{~mm}, \mathrm{~d}=350 \mathrm{~mm})\right)$.

${ }^{5,6}$ Table 1. The electric energy consumed by the network electric pumps during the heating season, $\mathrm{MW} \cdot \mathrm{h}$, for the temperature schedules ITS and ERS with a $40 \%$ share of the flow rate of delivery water when the regulation method changing at various diameters of pipelines and maximum temperatures of the delivery water.

${ }^{7,8}$ Table 2. The standardized heat losses $\Delta Q_{\text {loss }}^{\mathrm{s}}$ for temperature schedules ITS and ERS with a $40 \%$ share of the flow rate of delivery water when the regulation method changing.

${ }^{9,10}$ Table 3. Integral indicators of the investigated schedules at the district heating coefficient $\boldsymbol{\alpha}$ equal 0.5 at various diameters of pipelines and maximum temperatures of the delivery water with a $40 \%$ share of the flow rate of delivery water when the regulation method changing. 
${ }^{11,12}$ Table 4. Integral indicators of the investigated schedules at the district heating coefficient $\boldsymbol{\alpha}$ equal 1.0 at various diameters of pipelines and maximum temperatures of the delivery water with a $40 \%$ share of the flow rate of delivery water when the regulation method changing.

${ }^{13}$ Fig. 5. The ratio of the specific electricity generation based on heat consumption at ERS to at ITS at the district heating coefficient $\boldsymbol{\alpha}$ equal 0.5. The share of the flow rate of delivery water when the regulation method changing is $40 \%$.

${ }^{14}$ Fig. 6. Ratio of specific electricity generation based on heat consumption at ERS to at ITS at the district heating coefficient $\boldsymbol{\alpha}$ equal 1.0.The share of the flow rate of delivery water when the regulation method changing is $40 \%$.

${ }^{15}$ Fig. 7. Ratio of specific electricity generation based on heat consumption $E$ with the ERS at a $40 \%$ share of the flow rate of delivery waterwhen the regulation method changing at the district heating coefficient $\boldsymbol{\alpha}$ equal 0.5 .

${ }^{16}$ Fig. 8. Ratio of specific electricity generation based on heat consumption $E$ with the ERS at a $40 \%$ share of the flow rate of delivery water when the regulation method changing at the district heating coefficient $\boldsymbol{\alpha}$ equal 1.0.

\section{Литература (References)}

[1] Lauenburg P. Temperature optimization in district heating systems. Advanced District Heating and Cooling (DHC) Systems, Elsevier Ltd., 2016, pp. 223-240. doi:10.1016/B978-1-78242-3744.00011-2.

[2] Tunzi, M., Boukhanouf, R., Li, H., Svendsen, S., Ianakiev, A. Improving thermal performance of anexisting UK district heat network: a case for temperature optimization. Energy and Buildings, 2018, vol. 158, pp. 1576-1585.doi: 10.1016/j.enbuild.2017.11.049

[3] Chicherin S., Junussova L., Junussov T. [Minimizing the supply temperature at the district heating plant - dynamic optimization]. $20194^{\text {th }}$ International Conference on Advances in Energy and Environment Research (ICAEER 2019), vol. 118, 02004.doi: 10.1051/e3sconf/201911802004

[4] Guelpa E., Barbero G., Sciacovelli A., Verda V. Peak-shaving in district heating systems through optimal management of the thermal request of buildings. Energy, Elsevier, 2017, vol. 137(C), pp. 706-714. doi: 10.1016/j.energy.2017.06.107

[5] Schweiger G., Larsson P., Magnusson F., Lauenburg P., Velut S. District heating and cooling systems - Framework for Modelica-based simulation and dynamic optimization. Energy, Elsevier, 2017, vol. 137(C), pages 566-578. doi: 10.1016/j.energy.2017.05.115

[6] Arce I., López S., Perez S., Rämä M., Klobut K., Febres J. Models for fast modelling of district heating and cooling networks. Renewable and Sustainable Energy Reviews, Elsevier, 2018, vol.
82(P2), pp. 1863-1873. doi: 10.1016/j.rser.2017.06.109

[7] Romanchenko D., Odenberger M., Göransson L., Johnsson F. Impact of electricity price fluctuations on the operation of district heating systems: A case study of district heating in Göteborg, Sweden. Applied Energy, Elsevier, 2017, vol. 204(C), 30.doi:10.1016/j.apenergy.2017.06.092

[8] Bischi A., Taccari L., Martelli E., Amaldi E., Manzolini G., Silva P., Campanari S., Macchi E. A detailed MILP optimization model for combined cooling, heat and power system operation planning. Energy, 2014, vol. 74, pp. 12-26. doi: 10.1016/j.energy.2014.02.042

[9] Ovchinnikov P., Borodin A., Strelets K. Utilization potential of low temperature hydronic space heating systems: a comparative review. Building and Environment, 2017, vol. 112, pp. 88-98. doi: 10.1016/j.buildenv.2016.11.029

[10] Lauenburg P. Temperature optimization in district heating systems. Advanced District Heating and Cooling (DHC) Systems, Elsevier Ltd., 2016, pp. 223-240. doi: 10.1016/B978-1-78242-3744.00011-2

[11] Stevanovic V., Zivkovic B., Prica S., Maslovaric B., Karamarkovic V., Trkulja V. Prediction of thermal transients in district heating systems. Energy Conversion and Management, 2009, vol. 50:9, pp. 2167-73. doi: 10.1016/j.enconman.2009.04.034

[12] Pyatin A.A. Novaya model' regulirovaniya - teoreticheskaya osnova vysokoeffektivnogo otopleniya [New control model - The theoretical basis for high efficiency heating]. EKO-TEK - ECO-TECH, 2019, no. 1(70), pp. 1530.Available at: http://www.energysaving.ru/uploads/files/eko-tek_itog_70.pdf (accessed 31.10.2021) (in Russian).

[13] Pyatin A.A. Sbalansirovannoe otoplenie - novye vozmozhnosti effektivnosti i energosberezheniya [Balanced heating - New possibilities for efficiency and energy saving]. EKO-TEK - ECO$T E C H, 2018$, no. 3(68), pp. 23-34. Available at: http://www.e-nergy-saving.ru/uploads/files/168_3.pdf (accessed 31.10.2021) (in Russian).

[14] Pyatin A.A., Suvorov D.M. An Extended Heating Regulation Schedule: Definition and Assessment of Its Efficiency in Heat-Supply Systems. Thermal Engineering, 2021, vol. 68, no. 4, pp. 310323. doi: 10.1134/S0040363621040068

[15] Novitsky N.N., Shalaginova Z.I., Tokarev V.V., Grebneva O.A. Technology for the development of operating modes of large heat supply systems based on methods of multilevel thermohydraulic modeling. Izv. RAS. Energy, 2018, no. 1, pp. 1224.

[16] Shalaginova Z.I., Tokarev V.V. Applied Problems and Methodological Approaches to Planning and Implementation of Operating Condi- 
tions at District Heating Systems. Thermal Engineering, 2019, vol. 66, no. 10. pp. 714-729.

[17] Wang Y., You S., Zhang H., Zheng W., Zheng X., Miao Q. Hydraulic performance optimization of meshed district heating network with multiple heat sources. Energy, 2017, vol. 126, pp. 603621. doi:10.1016/j.energy.2017.03.044

[18] Guelpa E., Toro C., Sciacovelli A., Melli R., Sciubba E., Verda V. Optimal operation of large district heating networks through fast fluiddynamic simulation. Energy, 2016, vol. 102, pp. 586-595. doi: 10.1016/j.energy.2016.02.058

[19] Vesterlund M., Toffolo A., Dahl J. Optimization of multi-source complex district heating network, a case study. Energy, 2017, vol. 126, pp. 53-63. doi: 10.1016/j.energy.2017.03.018

[20] Vesterlund M., Dahl J. A method for the simulation and optimization of district heating systems with meshed networks. Energy Convers. Manage, 2015, vol. 89, no. 89, pp. 555-567. doi: 10.1016/j.enconman.2014.10.002

\section{Сведения об авторах.}
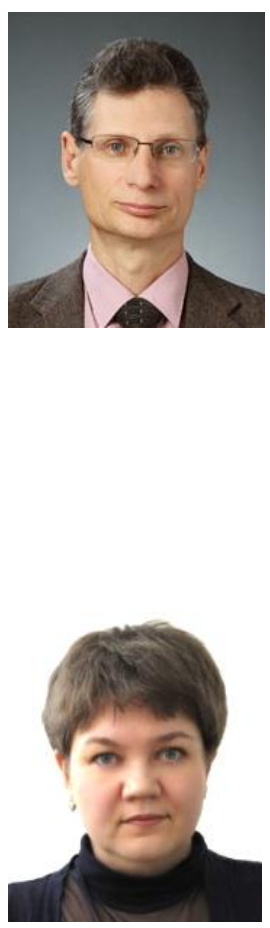

[21] Guelpa E., Sciacovelli A., Verda V. Thermo-fluid dynamic model of large district heating networks for the analysis of primary energy savings. Energy, 2017, vol. 184, pp. 33-44. doi:10.1115/IMECE2015-52315

[22] Gabrielaitiene I., Bøhm B., Sunden B. Modelling temperature dynamics of a district heating system in Naestved, Denmark - A case study. Energy Convers. Manage, 2007, vol. 48. no. 1, pp. 7886. doi: 10.1016/J.ENCONMAN.2006.05.011

[23] Gvozdenaca D., Urošević B.G., Menke Ch., Urošević D., Bangviwat A. High efficiency cogeneration: CHP and non-CHP energy. Energy, 2017, vol. 135, pp. 269-278. doi: 10.1016/j.energy.2017.06.143

[24] Simoyu L.L., Indurskii M.S., EfrosE.I. Calculation of the performance of the LP section in a cogeneration steam turbine under variable operating conditions. Thermal Engineering, 2000, vol. 47, no 2, pp.105-110.

\begin{abstract}
Суворов Дмитрий
Михайлович, кандидат технических наук, доцент, заведующий кафедрой теплотехники и гидравлики ВятГУ.

Научные интересы энергетическая эффективность теплофикации, оптимизация режимов работы ТЭЦ, энергосбережение E-mail: dmilar@mail.ru
\end{abstract}

Татаринова Наталья Владимировна,

кандидат технических наук, доцент кафедры теплотехники гидравлики ВятГУ.

Научные интересы теплофикация, математическое моделирование турбоустановок ТЭЦ

E-mail: nvt_s@mail.ru

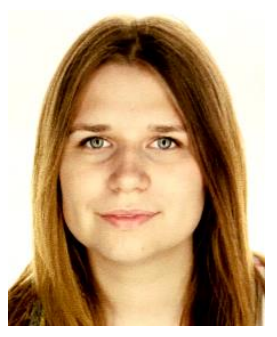

Лыскова Екатерина Алексеевна, магистрант ВятГУ.

Научные интересы математическое моделирование режимов работы тепловых сетей, энергосбережение.

E-mail: liskova.eka@yandex.ru 